\title{
Bioassays for coastal water quality: An assessment using the larval development of Haliotis midae $\mathrm{L}$
}

\author{
AL Shackleton ${ }^{1}$, DS Schoeman ${ }^{1 *}$ and BK Newman ${ }^{2}$ \\ ${ }^{1}$ Zoology Department, University of Port Elizabeth 6031, South Africa \\ 2 Zoology Department, University of Zululand, Private Bag x 1001, KwaDlangezwa 3886, South Africa
}

\begin{abstract}
The United States Environmental Protection Agency (USEPA) has established a suite of methods that use coastal invertebrate species as bioassay organisms to test industrial and domestic effluent as well as coastal waters for potential toxicity. Although these methods are used globally, the potential of such toxicity tests has not been adequately explored for South African coastal waters. This study serves to describe a simple, cost-effective and relatively quick testing procedure using the development of Haliotis midae larvae as a bioassay of coastal water quality. This test is based on the sensitivity of these larvae to low concentrations of zinc $(\mathrm{Zn})$. Its performance in a field trial demonstrates not only that this test has the potential to identify coastal waters of poor quality, but also that such identification could be of value in attempts to restock natural abalone populations, which are under extreme pressure from legal and illegal exploitation. Further work in this line should focus on the refinement of the methodology for this and other local species and should aim to contribute to the development of suitable criteria for the management of coastal water quality in South Africa.
\end{abstract}

\section{Introduction}

In many regions of the world, aquatic toxicity test data are routinely used to evaluate risks associated with the discharge of effluents from municipal and industrial treatment works into water bodies. This is in fact a legal obligation in many countries (Wells et al., 1998). Such tests can provide an indication of the potential toxicity of an effluent to biological communities inhabiting the receiving waters. Alternatively, toxicity tests can be used to evaluate the status of natural environments that might experience the impacts of other anthropogenic activities, such as harbour dredge sediment disposal and non-point source discharges (MacDonald et al., 1997). The development of scientifically sound protocols for toxicity testing is an extensive process. Not only does it require the identification of suitable candidate organisms, but also the establishment of appropriate and reproducible techniques with which to assess the sensitivity of these organisms to chemicals of anthropogenic origin. Although several workers have described the efficacy of using individual local marine species for toxicity testing purposes (Currie et al., 1974; Greenwood and Brown, 1974; Brown, 1974, 1976, 1982; Brown and Greenwood, 1978; Connell and Airey, 1979, 1982; Brown et al., 1982; Connell et al., 1991), this work focused on a limited number of species that were exposed to a restricted range of toxicants. The development of robust and generally applicable protocols for the assessment of South African marine and estuarine water quality has not received the attention that it deserves in the recent literature.

The most frequently applied procedure for assessing the toxicity of municipal and industrial effluents discharged to coastal waters in South Africa involves the use of gametes of local sea urchin species. This test, the so-called sea urchin fertilisation or sperm cell test, while widely applied throughout the world (Dinnel and Stober, 1987; Chapman, 1995; Beiras et al., 2001), has a major limitation

\footnotetext{
* To whom all correspondence should be addressed.

盄 041 504-2335; fax 041 504-2317; e-mail: zladss@zoo.upe.ac.za

Received 4 March 2002; accepted in revised form 19August 2002.
}

in that it provides only an indication of the short-term, acutely toxic effects of the effluent, thereby failing to consider longer-term, chronic (sublethal) impacts. It is for this reason that a battery of bioassays is usually used to comprehensively assess risks associated with the discharge of an effluent to receiving water biological communities. Such experimental arrays use species from a broad range of taxa and sensitivities, and analyse both acute and chronic effects. South African laboratories are in the process of adapting to this philosophy and currently supplement sea urchin gamete tests with longer-term tests, such as based on estuarine amphipods (Connell and Airey, 1979, 1982). However, there is still a need to expand upon and refine currently applied tests and test organisms used in South African coastal waters by incorporating as wide a range of different taxa as possible as well as by considering longer exposure periods and different test end-points.

Objectively evaluating the suitability of candidate organisms for toxicity testing purposes requires the comparison of biologically measurable responses (end-points) to a range of concentrations of a common reference toxicant. In this manner, the sensitivity of the various organisms can be ranked, and the most suitable species identified (USEPA, 1995). To be of practical use in such bioassays, a candidate species, or at least one of its life history stages, should not only be sensitive to potential contaminants, but should also be relatively easy to collect from the field (i.e. abundant) as well as amenable to routine maintenance, culture and rearing in the laboratory (Rand, 1995). If early developmental stages are to be used, spawning should be readily induced; otherwise gametes should be freely available from the natural habitat.

The larvae of the South African abalone, Haliotis midae L., meet most of the above criteria. Firstly, sperm and eggs are available at regular intervals from abalone-directed mariculture operations, ensuring a fairly regular supply of test material (although supply to the coast of KwaZulu-Natal might be more difficult than elsewhere). Secondly, $H$. midae larvae are relatively easy to maintain in the laboratory. Finally, larvae of $H$. midae are lecithotrophic (Leighton, 1974; Genade et al., 1988), and can thus be used in tests without having to provide food. This has numerous 


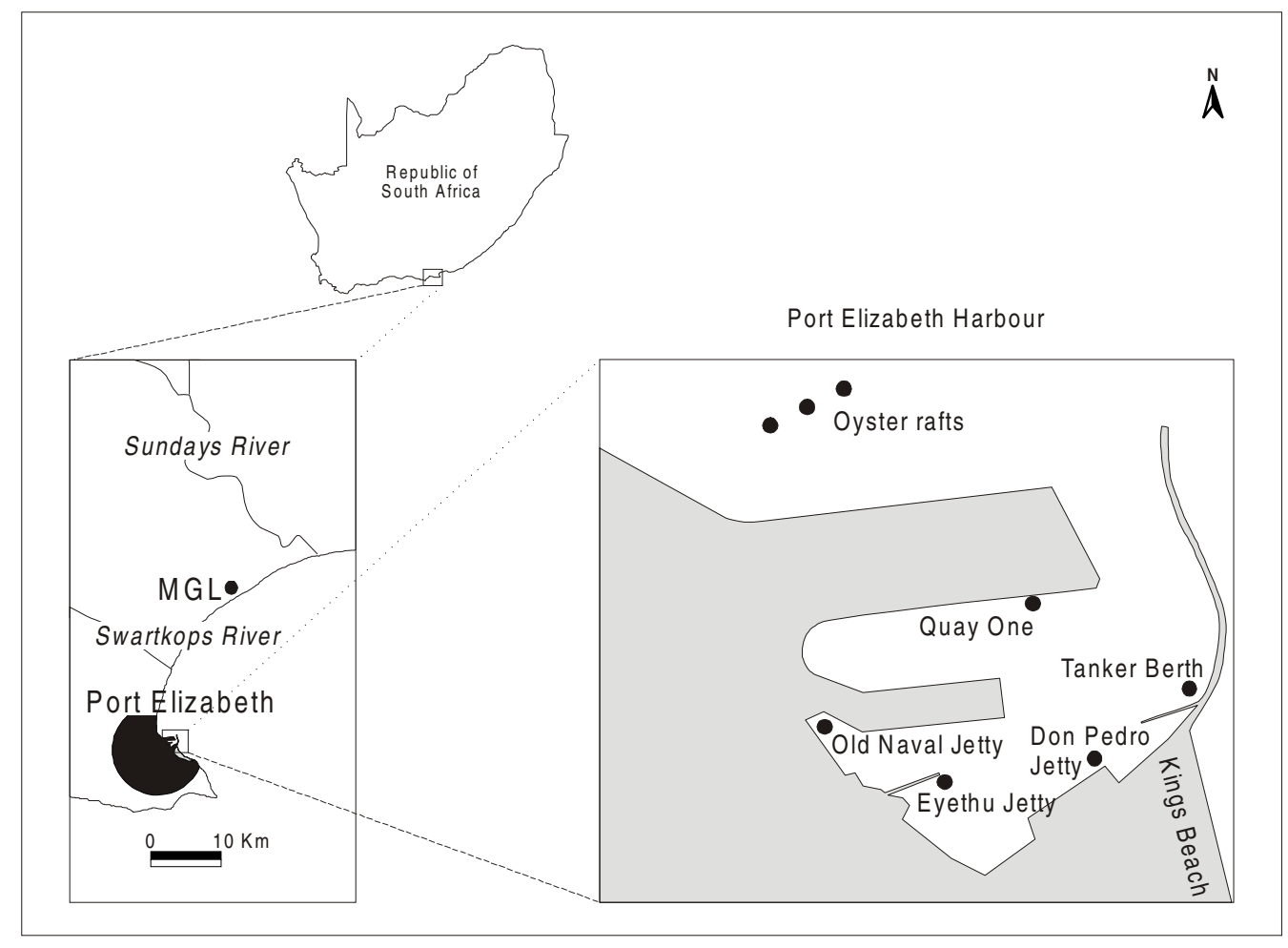

Figure1

Diagram illustrating study areas

benefits, but the most important is that toxins associated with food organisms can be excluded as causative agents of any observed toxic effect, thereby increasing the confidence with which this can be attributed to the toxicity of the test medium.

The only relevant information currently unavailable for $H$. midae larvae pertains to its sensitivity to pollutants of anthropogenic origin. Therefore, the objective of this study was to further assess the suitability of $H$. midae larvae as potential components of a comprehensive battery of bioassays by investigating their sensitivity to a single standardised toxicant, $\mathrm{Zn}$.

\section{Material and methods}

\section{Collection of test material}

Toxicity tests using $H$. midae larvae were based on the red abalone (H.rufescens) larval test outlined by the United States Environmental Protection Agency (USEPA, 1995). Because of suspected ecophysiological differences between the abalone species used, some aspects of the USEPA methodology were adapted to local conditions; principally a different rearing temperature.

Newly spawned $H$. midae gametes were collected from Marine Growers Ltd., an abalone mariculture farm situated about $45 \mathrm{~km}$ east of Port Elizabeth (Fig. 1). Here, wild-caught and captive-bred adults are held in a hatchery, males and females maintained separately to avoid chance fertilisation events. Abalone were induced to spawn by exposure to dilute hydrogen peroxide $\left(\mathrm{H}_{2} \mathrm{O}_{2}\right)$ in Tris-buffered seawater (Morse, 1984; USEPA, 1995) at $18^{\circ} \mathrm{C}$. The pooled sperm of 11 wild and 13 captive-bred males were collected, as were the pooled eggs of 12 captive-bred females.

The gametes were transported to the laboratory in an insulated container to prevent rapid temperature fluctuations. Inside this container, $500 \mathrm{ml}$ pyrex bottles containing gametes were cushioned in a soft towel to minimise vibrations that might otherwise have caused the spontaneous formation of fertilisation membranes. The effectiveness of this protocol was confirmed in the laboratory through microscopic investigation of egg samples.

\section{Laboratory procedure}

All laboratory procedures used glassware that had been cleaned according to USEPA (1995) standards. Experiments were conducted in an environmentally controlled room with a light:dark cycle of $12: 12 \mathrm{~h}$ and a temperature of $20^{\circ} \mathrm{C}$. A fertilisation solution was prepared by adding $10 \mathrm{~m} \ell$ of sperm solution to $60 \mathrm{~m} \ell$ of $1 \mu \mathrm{m}$ filtered natural seawater in a $100 \mathrm{~m} \ell$ glass beaker. To this was added $25 \mathrm{~m} \ell$ of concentrated eggs. The gamete solution was allowed to stand for 15 min to facilitate fertilisation, after which the resulting embryos were rinsed to remove excess sperm, which might otherwise have caused polyspermy. The rinsing process involved siphoning the supernatant, containing free-swimming sperm, from above settled embryos, adding $1 \mu \mathrm{m}$ filtered natural seawater to volume before allowing a further $15 \mathrm{~min}$ for settling, and repeating of the rinsing process. Following the final rinsing, the embryos were allowed to settle before they were delivered to the test solutions in an ad hoc manner (no detailed counts were made of the number of embryos delivered).

The test procedure assessed the sensitivity of $H$. midae larvae to a single reference toxicant: $\mathrm{Zn}$. This analysis constituted a positive control, permitting comparisons to other species exposed to this same reference toxicant, while simultaneously providing a means of confirming that the test procedures met test acceptability criteria specified by the USEPA (1995).

The experiment was laid out in a simple randomised design, with five replicates of each of six treatments. These treatments were a negative control ( $1 \mu \mathrm{m}$ filtered natural seawater) and five serial dilutions $\left(100 \mu \mathrm{g} \cdot \ell^{-1} ; 56 \mu \mathrm{g} \cdot \ell^{-1} ; 32 \mu \mathrm{g} \cdot \ell^{-1} ; 18 \mu \mathrm{g} \cdot \ell^{-1}\right.$ and 10 $\left.\mu \mathrm{g} \cdot \ell^{-1}\right)$ of a $10000 \mu \mathrm{g} \cdot \ell^{-1} \mathrm{Zn}$ stock, brought to solution in $1 \mu \mathrm{m}$ filtered natural seawater using $\mathrm{ZnCl}_{2} \mathrm{H}_{2} \mathrm{O}$ (USEPA, 1995). Replicates were prepared in $30 \mathrm{~m} \ell$ glass specimen vials $(60 \mathrm{~mm}$ length and 25 
$\mathrm{mm}$ internal diameter), each containing $15 \mathrm{~m} \ell$ of the appropriate test solution. To each of these vials, $2 \mathrm{~m} \ell$ of rinsed abalone embryos were added. To establish the proportion of unfertilised eggs introduced to the treatments, a sample was removed from the fertilisation beaker at the start of the experiment and inspected under a dissection microscope.

The test was terminated after $40 \mathrm{~h}$, using a $20 \%$ formalin solution to arrest larval development. Because the operculate veliger stage [as classified by Leighton (1974)] was considered to be the end-point of this test, specimens that failed to fully develop a primary shell were assumed to have been negatively affected by one or more factors. For each replicate, the sensitivity of $H$. midae larvae to the test solutions was measured in relation to the proportion of fertilised eggs that had developed into operculate veligers. This was accomplished by noting the proportion of unfertilised eggs, early veliger larvae and operculate veligers among the first 100 randomly collected eggs or embryos encountered during microscopic examination of samples from each replicate. Wherever fewer than 100 eggs/embryos were added to a replicate, all were examined. The test thus assesses the development rate of larvae, rather than mortality.

\section{Field application of the test}

To assess the performance of the toxicity test under field conditions, the relative sensitivity of $H$. midae larvae to coastal waters that we perceived to be of poor quality was determined. Samples of such waters were collected from five sites within the Port Elizabeth Harbour that were of concern to the National Ports Authority of South Africa's (NPASA) Environmental Management Office. These samples were collected from $0.5 \mathrm{~m}$ below the water surface at: the Tanker Berth; the Don Pedro Jetty; the Eyethu Jetty; the Old Naval Jetty and Quay One, which is a container loading depot (Fig. 1). Because harbour water quality is highly variable in space and time (Ndlovu, 2001), using such water sources provides a reasonable preliminary appreciation of the lower range of water qualities that might be encountered in nature. Toxicity testing was conducted as before, but with $15 \mathrm{~m} \ell$ of harbour water in place of the reference toxicant.

\section{Data analysis}

Comparisons among proportions of $H$. midae larvae reaching the operculate veliger stage within the test period in different test solutions were made using one-way ANOVA. Proportion data (percent operculate veliger stage larvae) were normalised by arcsinetransformation prior to performing ANOVA (Zar, 1999). Where appropriate, Student-Newman-Keuls post hoc tests where used to identify differences in larval development rate among treatments. To investigate the relationship between the success with which the test end-point was reached and the concentration of the reference toxicant, a concentration-response curve was constructed using BenchMark Dose Software (Freeware available at http://epa.gov/ ncea/bmds.htm). The continuous Hill formulation was selected, because it models a measure without regard for "adversity". This was important, because the response variable used here measured the number of individuals assumed to be unaffected by the toxicant, rather than those affected, as is the case in most of the other model options. Data input to the model were the number of replicates per treatment and the mean proportional occurrence of the test endpoint, with its attendant standard deviation. Because zero-responses caused computational errors, all response data were transformed by adding $1 \times 10^{-6}$.

\section{Results}

The reference toxicant test procedure satisfied all test acceptability criteria defined by the USEPA (Table 1). Consequently, complete analyses of the results were justified. Because no operculate veligers were observed in the $100 \mu \mathrm{g} \cdot \ell^{-1} \mathrm{Zn}$ treatment, these data were excluded from ANOVA. The proportion of $H$. midae larvae reaching the test end-point in the remaining reference toxicant solutions differed significantly among all treatments (ANOVA: F $=222.518 ; \mathrm{DF}=3,16 ; \mathrm{p}<0.001)$, with only one exception: the control and $10 \mu \mathrm{g} \cdot \ell^{-1} \mathrm{Zn}$ treatment did not differ (Student Newman Keuls: $\mathrm{p}>0.05)$.

The relationship between the toxicant concentration and the corresponding development success was appropriately modelled by the Hill function (Fig. 2). This fitted model suggests that the proportion of fertilised eggs reaching the operculate veliger stage relative to that of the control would halve (EC50) at a toxicant concentration of $12.9 \mu \mathrm{g} \cdot \ell^{-1} \mathrm{Zn}$.

\begin{tabular}{|c|c|}
\hline \multicolumn{2}{|c|}{$\begin{array}{l}\text { TABLE } 1 \\
\text { A summary of the test acceptability criteria for the } \\
\text { Haliotis midae bioassay. Normality is defined as the } \\
\text { success in reaching the test end-point. }\end{array}$} \\
\hline USEPA criteria & $\begin{array}{l}\text { H. midae } \\
\text { response }\end{array}$ \\
\hline $\begin{array}{l}\text { Mean larval normality must be at least } \\
80 \% \text { in the control. } \\
\text { The response from the } 56 \mu \mathrm{g} \cdot \ell^{-1} \text { treatment } \\
\text { must be significantly different from the } \\
\text { control. } \\
\text { The minimum significant difference } \\
\text { ( } \% \text { MSD) is }<20 \% \text { relative to the control } \\
\text { for the reference toxicant. }\end{array}$ & $80 \%$ normality \\
\hline
\end{tabular}

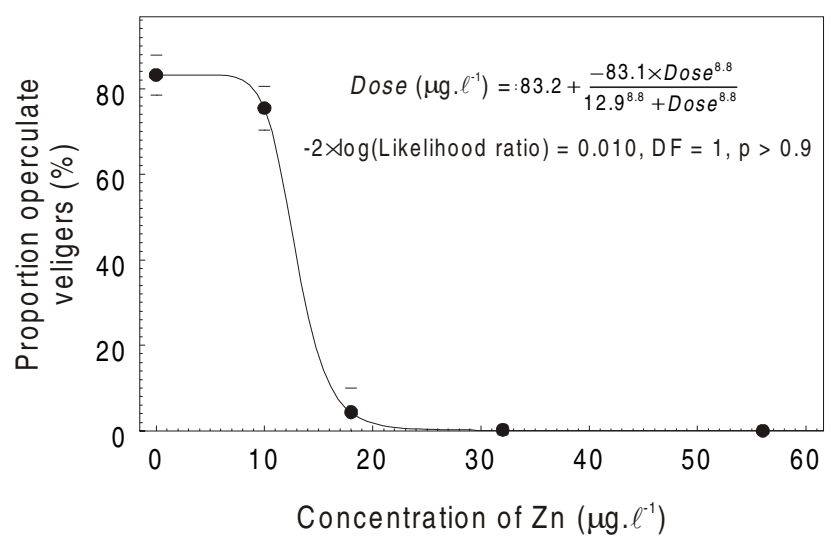

Figure 2

The fitted dose-response curve illustrating the relationship between the success with which the test end-point was reached and the concentration of the reference toxicant. Model formulation and relevant statistics are included as an inset; error bars indicate standard deviation input to the model. 


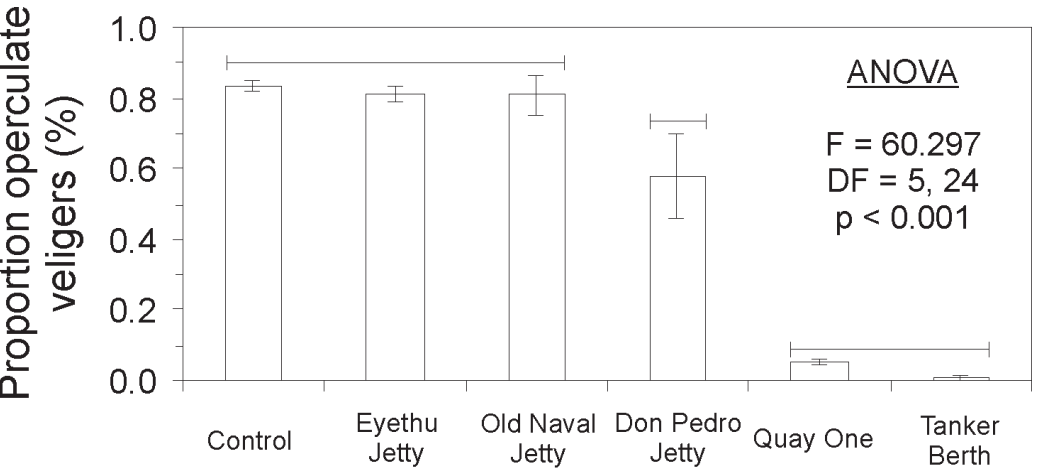

\section{Sample site}

The field trial of the toxicity test revealed significant differences among the treatments (Fig. 3). Larval response to the water samples from the Eyethu and Old Naval Jetties did not differ from those in the control. However, development success was significantly lower in water from the Don Pedro Jetty, and lower still in waters from Quay One and the Tanker Berth (Fig. 3).

\section{Discussion}

The results of the present study demonstrate that $H$. midae larval development has the potential to serve as a useful bioassay for toxicological testing of South African coastal waters; not only were larvae sensitive to the reference toxicant, but they also demonstrated sensitivity to water samples of impaired quality collected from the field. Although the reference toxicant test procedure satisfied all test acceptability criteria defined by the USEPA (USEPA, 1995), it is apparent from the fitted concentration-response curve that the serial dilutions of the reference toxicant spanned too wide a range of concentrations. These concentrations were based on USEPA (1995) recommendations for testing with $H$. rufescens larvae. Results of the present study suggest that $H$. midae larvae are considerably more sensitive to the $\mathrm{Zn}$ reference toxicant than $H$. rufescens larvae, the latter showing a Zn EC50 of about $44 \mu \mathrm{g} \cdot \ell^{-1}$ (Hunt et al. 1998). Future development of the H. midae larval toxicity test should thus focus on lower $\mathrm{Zn}$ concentrations, centred on $12.9 \mu \mathrm{g} \cdot \ell^{-1} \mathrm{Zn}$.

The response of $H$. midae larvae to water samples collected from the Port Elizabeth Harbour confirmed that water in some parts of the harbour was of a low quality, and that water quality is highly variable over small spatial scales. Whereas water at the Eyethu and Old Naval Jetties was not measurably detrimental to $H$. midae larvae, development rates in the water samples collected from the other stations were significantly slower. Significantly fewer operculate veligers were found in water samples from the Don Pedro Jetty, while the quality of the water in samples from both the Tanker Berth and Quay One was so poor that very few larvae were able to reach the operculate veliger stage within the test period. The reason for these differences is uncertain. Potential explanations notwithstanding, the water quality of the Tanker Berth and Quay One should be viewed with some concern from an environmental management perspective. Harbours are open systems and are under the direct influence of tidal pulsing. If water quality is not maintained at reasonably high levels, adjacent marine ecosystems might be exposed to contamination. This is of particular concern around the Port Elizabeth Harbour due to the proximity of popular recreational beaches, diverse rocky reefs and mariculture operations (Fig. 1). While the above discussion pertains to the Port Elizabeth Harbour only, it is clear that this test also represents a useful and easily applicable method for determining the suitability of coastal waters

\section{Figure 3}

Comparison of the proportion of fertilised eggs reaching the test end-point in water samples from various sites within the Port Elizabeth Harbour. Relevant statistics are included as an inset, error bars indicate standard error $(\mathrm{n}=5)$ and horizontal lines demarcate homogenous groups, as indicated by SNK post hoc tests. for the introduction of abalone by agencies attempting to enhance local stocks. This is important because local stocks of this valuable commodity are severely depleted (Tarr et al., 1996; Tarr, 2000) and research efforts are currently being channelled into developing methods to restock areas that have low adult abundance and high exploitation rates (Cook, 1998; Sweijd et al., 1998; Mayfield et al., 2001). Unsuitable habitats for reintroduction could be simply identified by larval development rates significantly lower than those in $1 \mu \mathrm{m}$ filtered natural seawater. Should water quality not be suitable for the larvae, further expenditure need not be incurred in investigating other features of a site, because any environment that cannot maintain reproductive processes of a species also cannot sustain viable populations in the long term.

Although the data from the present study indicate that $H$. midae larvae are well suited to use in toxicity tests, this should be viewed as only the first of many stages in the development of this specific test. Future research in this respect should focus on: the effects of rearing temperature on developmental rate and response to the reference toxicant; potential differences in response between spatially separated populations of $H$. midae; and the reproducibility of the test procedure under laboratory conditions. This should be supported by the development of an array of bioassays for coastal water quality using additional candidate organisms.

\section{Acknowledgements}

Financial aid and provision of logistics and laboratories by the Department of Zoology, University of Port Elizabeth and by the NRF are greatly appreciated. Wendy Todkill is acknowledged for her assistance in digitising the PE Harbour map, as are Mrs Berny Snow and two anonymous referees for their critical assessment of manuscript drafts. Marine Growers Ltd. and the National Ports Authority of South Africa are thanked for their co-operation during the period of experimentation.

\section{References}

BEIRAS R, VÁZQUEZ E, BELLAS J, LORENZO JI, FERNÁNDEZ N, MACHO G, MARIÑO JC and CASAS L (2001) Sea urchin embryo bioassay for in situ evaluation of the biological quality of coastal seawater. Est. Coast. Shelf Sci. 52 29-32.

BROWN AC (1974) Observations on the effect of ammonium nitrate solutions on some common marine animals from Table Bay. Trans. $R$. Soc. S. Afr. $41217-223$.

BROWN AC (1976) Toxicity studies on marine animals. S. Afr. J. Sci. 72 197-199.

BROWN AC (1982) Pollution and the sandy-beach whelk Bullia. Trans. $R$. Soc. S. Afr. 44 555-562.

BROWN AC and GREENWOOD PJ (1978) Use of sea-urchin Parechinus angulosus (Leske) in determining water quality and acceptable pollution 
levels for the South African marine environment. S. Afr. J. Sci. 74 102-103.

BROWN AC, DAVIES KC and YOUNG DJ (1982) Effects of cadmium and zinc on oxygen uptake in the whelk Bullia digitalis (Dillwyn). Trans. R. Soc. S. Afr. 44 551-554.

CHAPMAN GA (1995) Sea urchin sperm cell test. In: Rand GM (ed). Fundamentals of Aquatic Toxicology. Taylor and Francis, Washington. 189-205.

CONNELL AD and AIREY DD (1979) Life cycle bioassays using two estuarine amphipods Grandidierella lutosa and G. lignorum to determine detrimental sublethal levels of marine pollutants. S. Afr. J. Sci. 75 313-314.

CONNELL AD and AIREY DD (1982) The chronic effects of fluoride on the estuarine amphipods Grandidierella lutosa and G. lignorum. Water Res. 16 1313-1317.

CONNELL AD, AIREY DD and RATHBONE P-A (1991) The impact of titanium dioxide waste on fertilization in the sea urchin Echinometra mathaei. Mar. Pollut. Bull. 22 119-122.

COOK P (1998) The current status of abalone farming in South Africa. J. Shellfish Res. 17 601-602.

CURRIE AB, BROWN AC and BENNET GR (1974) The effect of ammonium nitrate solutions on some aspects of the biology of the black mussel, Choromytilus meridionalis. Trans. R. Soc. S. Afr. 41 209-215.

DINNEL PA and STOBER QJ (1987) Application of the sea urchin sperm bioassay to sewage treatment efficiency and toxicity in marine waters. Mar. Env. Res. 21 121-133.

GENADE AB, HIRST AL and SMITH CJ (1988) Observations on the spawning, development and rearing of the South African abalone Haliotis midae Linn. S. Afr. J. Mar. Sci. 6 3-12.

GREENWOOD PJ and BROWN AC (1974) Effect of ammonium nitrate solutions on fertilization and development of the sea urchin, Parechinus angulosus. Zool. Afr. 9 (2) 205-209.

HUNT JW, ANDERSON BS and PHILLIPS BM (1998) Recent advances in microscale toxicity testing with marine mollusks. In: Wells PG, Lee $\mathrm{K}$ and Blaise $\mathrm{C}$ (eds.). Microscale Testing in Aquatic Toxicology: Advances Techniques and Practice. CRC Press, Washington. 423-436.
LEIGHTON DL (1974) The influence of temperature on larval and juvenile growth of three species of southern California abalones. Fishery Bull., Wash. 70 (2) 1137-1145.

MACDONALD DA, MATTA MB, FIELD LJ, CAIRNCROSS C and MANNMD(1997) The Coastal Resource Co-ordinators Bioassessment Manual. Report No. HAZMAT 93-1. NOAA Hazardous Response Assessment Division. Seattle. 3-1 - 3-17.

MAYFIELD S, DE BEER E, BRANCH GM (2001) Prey preference and the consumption of sea urchins and juvenile abalone by captive rock lobsters (Jasus lalandii). Mar. Freshwater Res. 52 773-780.

MORSE DE (1984) Biochemical and genetic engineering for improved production of abalones and other valuable molluscs. Aquacult. 39 (1-4) 263-282.

NDLOVU T (2001) Personal communication. National Ports Authority of South Africa, Port Elizabeth, South Africa.

RAND GM (1995) Fundamentals of Aquatic Toxicology: Effects, Environmental Fate and Risk Assessment. Francis and Taylor. Washington. $1125 \mathrm{pp}$.

SWEIJD N, SNETHLAGEQ, HARVEY D, COOK P (1998) Experimental abalone (Haliotis midae) seeding in South Africa. J. Shellfish Res. 17 (3) 897-904.

TARR RJQ (2000) The South African abalone (Haliotis midae) fishery: A decade of challenges and change. In: Cambell A (ed.) Workshop on Rebuilding Abalone Stocks in British Colombia. Can. Spec. Publ. Fish. Aquat. Sci. 130 32-40.

TARR RJQ, WILLIAMS PVG and MACKENZIE AJ (1996) Abalone, sea urchins and rock lobster: A possible ecological shift that may affect traditional fisheries. S. Afr. J. Mar. Sci. 17 319-323.

USEPA (1995) Short-Term Methods for Estimating the Chronic Toxicity of Effluents and Receiving Waters to West Coast Marine and Estuarine Organisms. National Exposure Research Laboratory, Office of Research and Development. United States Environmental Protection Agency. Cincinnati. 648 pp.

WELLS PG, LEE K and BLAISE C (1998) Microscale Testing in Aquatic Toxicology: Advances Techniques and Practice. CRC Press. Washington. 679pp.

ZAR JH (1999) Biostatistical Analysis (4 ${ }^{\text {th }}$ edn.). Prentice Hall, Inc. New Jersey. 663 pp. 
